\title{
An observing system for the collection of fishery and oceanographic data
}

\author{
P. Falco ${ }^{1}$, A. Belardinelli ${ }^{1}$, A. Santojanni ${ }^{1}$, N. Cingolani $^{1}$, A. Russo ${ }^{2}$, and E. Arneri ${ }^{1}$ \\ ${ }^{1}$ Istituto di Scienze Marine- Consiglio Nazionale delle Ricerche, Sede di Ancona, Largo Fiera della Pesca 60125, Ancona, \\ Italy \\ ${ }^{2}$ Dipartimento di Scienze del Mare, Università Politecnica della Marche, Via Brecce Bianche, 60131, Ancona, Italy
}

Received: 18 May 2006 - Published in Ocean Sci. Discuss.: 13 July 2006

Revised: 11 October 2006 - Accepted: 7 April 2007 - Published: 2 May 2007

\begin{abstract}
Fishery Observing System (FOS) was developed as a first and basic step towards fish stock abundance nowcasting/forecasting within the framework of the EU research program Mediterranean Forecasting System: Toward an Environmental Prediction (MFSTEP). The study of the relationship between abundance and environmental parameters also represents a crucial point towards forecasting. Eight fishing vessels were progressively equipped with FOS instrumentation to collect fishery and oceanographic data. The vessels belonged to different harbours of the Central and Northern Adriatic Sea. For this pilot application, anchovy (Engraulis encrasicolus, L.) was chosen as the target species. Geo-referenced catch data, associated with in-situ temperature and depth, were the FOS products but other parameters were associated with catch data as well. MFSTEP numerical circulation models provide many of these data. In particular, salinity was extracted from re-analysis data of numerical circulation models. Satellite-derived sea surface temperature (SST) and chlorophyll were also used as independent variables. Catch and effort data were used to estimate an abundance index (CPUE - Catch per Unit of Effort). Considering that catch records were gathered by different fishing vessels with different technical characteristics and operating on different fish densities, a standardized value of CPUE was calculated. A spatial and temporal average CPUE map was obtained together with a monthly mean time series in order to characterise the variability of anchovy abundance during the period of observation (October 2003-August 2005). In order to study the relationship between abundance and oceanographic parameters, Generalized Additive Models (GAM) were used. Preliminary results revealed a complex scenario: the southern sector of the domain is characterised by a stronger relationship than the central and northern sector where the interactions between the environment and the an-
\end{abstract}

Correspondence to: P. Falco

(p.falco@ismar.cnr.it) chovy distribution are hidden by a higher percentage of variability within the system which is still unexplained.

GAM analysis showed that increasing the number of explanatory variables also increased the portion of variance explained by the model. Data exchange and interdisciplinary efforts will therefore be crucial for the success of this research activity.

\section{Introduction}

The analysis of the relationships between environmental conditions and the distribution of fish stocks is a complex matter. Many studies have pointed out how the environment and its variability can influence recruitment and fish distribution (Cushing, 1996; O'Brien et al., 2000; Attrill and Power, 2002; Chavez et al., 2003). Although fishing effort has grown in the recent past and is currently increasing, there is evidence that climate and environmental variability could determine large fluctuations in fish stocks. To add more complexity, the state of relationships between climate/environment and stocks could not be conclusive (Mann, 1993): it looks like they persist for one or two decades to then evolve to another state as consequence of the changing environmental conditions (Klyashtorin, 2001).

Realistic estimates regarding how fish stock abundance changes in time and space are not easy to obtain. Acoustic surveys (Swartzman et al., 1992; Daskalov, 1999; Hedger et al., 2004) are the main experimental method used to collect information about stock abundance of small pelagic fish; also, information regarding landings can be of help in this evaluation (Denis et al., 2002). On the other hand, temporal coverage of survey data is not appropriate because it is not always possible to carry out surveys regularly. In addition, surveys do not cover the spatial extent of the stock adequately. The main issue to overcome when using landings data is the delayed availability of this information, when,

Published by Copernicus GmbH on behalf of the European Geosciences Union. 
for management purposes, it would be needed almost in real time. Moreover relating position to catches it is not always possible in the case of landings data. Catches can also be obtained by means of specific forms distributed among the fishing fleet of one or more harbours. In this case skippers of the fishing vessels are required fill in the forms with all the required information at the end of each fishing day. This approach may fail because fishermen can not guarantee the required attention for time-spans long enough to create appropriate time series.

Furthermore, in order to yield abundance data with time and spatial resolutions comparable with environmental data, fishery observing systems need to be improved using more advanced tools.

Generally, a good and appropriate observing system is fundamental in order to implement models to nowcast/forecast the behaviour of the marine environment and the evolution of parameters connected with it. Nowcast of fish abundance is crucial for management. The use of traditional models (e.g. Beverton and Holt, 1957) in the past did not avoid the decline of very exploited fish stocks (Pauly et al., 2002), thus the need to accomplish models which consider each single aspect of the problem, has become more and more important.

Fisheries nowcasting/forecasting is at a very preliminary stage and the number of variables involved to predict abundances of life stages (or age classes) of one species is high. Onet way to address the problem would consist in the realisation of a fish module in the existing and developing models of hydrodynamics and ecosystem. Population dynamics of fish are complicated in their interactions with the natural system; mortalities, by predation and/or by fishing for each life stage, are not easy to measure. A preliminary, fundamental, step toward fishery forecasting for management purposes would thus be the set up of an automated Fishery Observing System (FOS). In this paper a new kind of FOS is presented and discussed.

Typically the fishery sector has been considered as end user of the products and information deriving from oceanographic research activity whereas its role as possible data source has been largely ignored (Simpson, 1994). The idea here is that fishermen become part of the observing system, not only because they can provide us with catch information but also because the use of their daily presence at sea for collecting environmental data could open the way to a new kind of ship of opportunity.

The FOS was tested in the Adriatic Sea. Data collection started in August 2003 and it is still ongoing. This paper presents the data collected until the end of August 2005.

The long-term objective is that of developing a short term forecasting system for fish stock abundance in the Adriatic Sea, extendable to other marine regions and species. In this pilot application the species selected is mainly anchovy ( $E n$ graulis encrasicolus, L.), one of the most important commercial species, being the target of an important fishery in the northern and central Adriatic Sea with an annual catch fluctuating, at present, between 20000 and 30000 tonnes (Santojanni et al., 2003). The Adriatic Sea was chosen among the Mediterranean fishing areas for anchovy for three important reasons: it is the principal fishing area for this species, it is a continental basin (so relatively easy to monitor and with limited lateral advection), it is covered by regional and shelf MFSTEP models.

The paper is organized as follows: the second section provides a brief description of the status of the anchovy fishery in the Adriatic sea; in Sect. 3, the Fishery Observing System (FOS) is described and discussed along with some information regarding the data set used, the methodology used to derive the abundance index and the statistical models used to study the relationship between abundance index and environmental parameters; preliminary results are discussed in Sect. 4.

\section{Anchovy fishery in the Adriatic Sea}

Anchovy (Engraulis encrasicolus, Linnaeus) caught by the Italian Adriatic fishing fleet represents $90 \%$ of the total catch in the Adriatic Sea and 24\% of the total Mediterranean catch (Santojanni et al., 2003; Cingolani et al., 2004). The value of Adriatic anchovy landed catches was estimated at about $35 \mathrm{MECU}$ in 1998. The importance of this species is thus obvious. The choice of anchovy as target species of this study is not only related to its economical importance but also to two other basic reasons: (1) its short life span and the dependence of year class strength on recruitment will allow the use of these data to model possible relationships between environmental parameters and recruitment; (2) the fact that anchovy is zooplanktophagous means it is directly linked to a lower trophic level which could be the final result of current investigation on bio-physical modelling (Vichi et al., 1998).

Anchovy mainly spawns from spring to autumn throughout the northern and central Adriatic and juveniles concentrate in shallow waters (less than $30 \mathrm{~m}$ depth) along the Italian coasts (Regner, 1996). Few months after recruitment, anchovy already reaches commercial size. Knowledge of how anchovies interact with environmental variables, especially temperature, salinity, density, stratification, fronts and other biological variables such as zooplankton, is necessary. This has not yet been achieved because, while increasingly accurate 3-D fields of environmental variables are available daily as model forecast and hindcast outputs, there is very limited (spatial and/or temporal) information about the geographical distribution of anchovies and their daily variations. A new kind of FOS is thus also intended to fill in this gap.

The Italian fishing fleet for small pelagics is distributed all along the Adriatic coast and two kinds of fishing gear are currently used: mid water pelagic trawl nets towed by two vessels (volante in Italian) and light attraction purse seines (lampara in Italian). The same fishing gear catches 
anchovy (Engraulis encrasicolus L.) but also sardine (Sardina pilchardus Walb.) and to a lesser extent other pelagic fish such as sprat (Sprattus sprattus L.), horse mackerel (Trachurus spp.) and mackerel (Scomber spp.). The volante is mainly used in the northern and central Adriatic. At present approximately 50 couples of fishing vessels use this gear; their average engine power is $400 \mathrm{HP}$, average size of the vessels is 54 GRT but there are wide variations in size and engine power. Lampara vessels ( 25 boats, 40-80 GRT) operate in the Central Adriatic, south of Ancona. Here it is almost common for a fishing vessel to switch from lampara during the summer season (when there are favourable weather conditions for this fishing technique) to pelagic trawl for the remaining part of the year. During the lampara fishing season (April/May-November) some fishing vessels registered in southern Adriatic move into the Central Adriatic increasing the lampara fishing fleet up to a total of about 50/55 boats. Smaller lampara (17 boats) operate in the Gulf of Trieste.

Anchovy fishery experienced a sudden collapse in 1987, when only $3700 \mathrm{t}$ were landed. Evidence from assessments suggests that the collapse was caused by very low recruitment. This was probably due to environmental factors determining the level of recruitment (Cingolani et al., 1996; Santojanni et al., 2006). Since then, total annual catches of anchovy has increased but a complete recovery did not occur. It is thus important to devise an integrated system able to collect information regarding both fish stock abundance and environmental parameters.

\section{Material and methods}

\subsection{Fishery observing system}

The development of the FOS was based on the need to obtain all possible data without impacting too much on the fishing activity (condition necessary in order to obtain fishermen's collaboration). The FOS, in its last version, consists mainly of three components: an electronic logbook (EL), a GPS and a temperature and pressure recorder (Fig. 1). The latter two components are available on the market whilst the EL was developed ad hoc for this application although standard electronic components were used to build it. Each single component of the FOS generates a file: catch and position data are stored on the EL, temperature and depth data are stored on the memory of the sensor. Temperature data are collected every time the fishing gear is hauled; they have different patterns depending on which kind of fishing technique is used as it will be pointed out subsequently. Eventually, all data are stored in a database and collated.

\subsubsection{Electronic logbook and positioning}

The core component of FOS is the EL, in particular this is a computer with a touch screen as user interface. The EL has

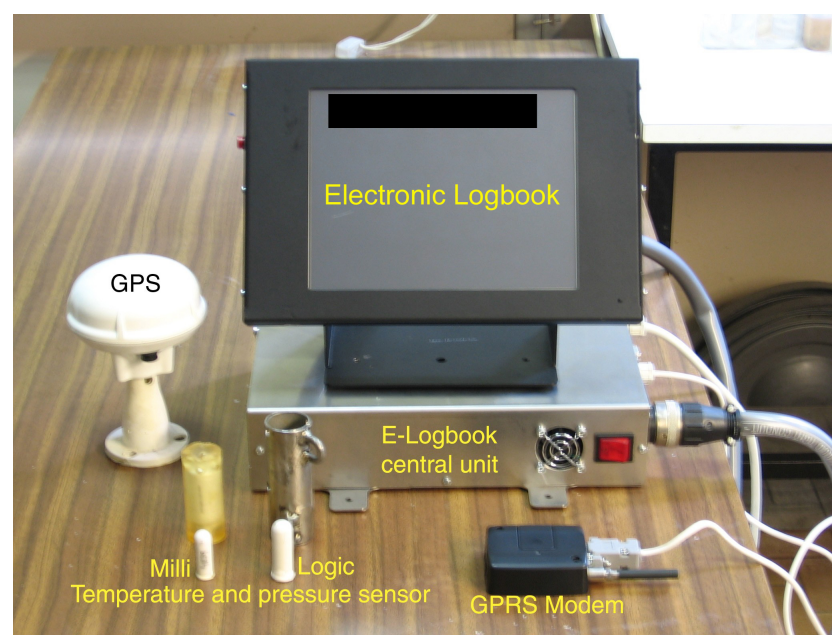

Fig. 1. FOS components.

been strongly modified from the initial version. In the last version, as showed in Fig. 1, it is made up by two separate components, the screen and the central unit. In this way it does not take up too much room and it looks like common equipment installed on the deck of the fishing vessel. The central unit is very compact and allows different installation solutions. A very compact mainboard (VIA EPIA PD-Series Mini-ITX) was used in order to maintain a reduced size of the central unit. It features four serial communication ports and up to six 2.0 USB connections. In our application only one USB port, for direct data downloading or to connect external devices (keyboard, mouse, etc...) and three serial com ports, to get permanent connection with the screen, the GPS and an external modem, are needed. The latter allows data transmission to a remote computer via a GPRS/GSM connection. The production of the EL was carried out by ASYSTEL of Trevi - Italy.

Catch data are input by means of a dedicated software, programmed to be as user friendly as possible, where only the essential information are required for input. Information regarding the species are required. They are indicated by the software and for each species the skipper enters only the total catch for haul, an estimate of the mean size of individuals in the catch (this information is required only for anchovy and sardine) and the discards (in terms of catch and size). In order to simplify this process, the measure unit of catches was established as boxes of fish and the mean size is expressed in number of fishes per kilogram for anchovy and in two categories for sardine: large or small. These are the common ways used by fishermen in the Adriatic to indicate catch and mean size for these two species. In the post-processing phase, catches are converted in $\mathrm{kg}$ using a known conversion factor between boxes and $\mathrm{kg}$. This factor generally differs from harbour to harbour.

A CMC Electronics Smart GPS antenna is connected with and powered by the EL. Thus every time the EL is switched 


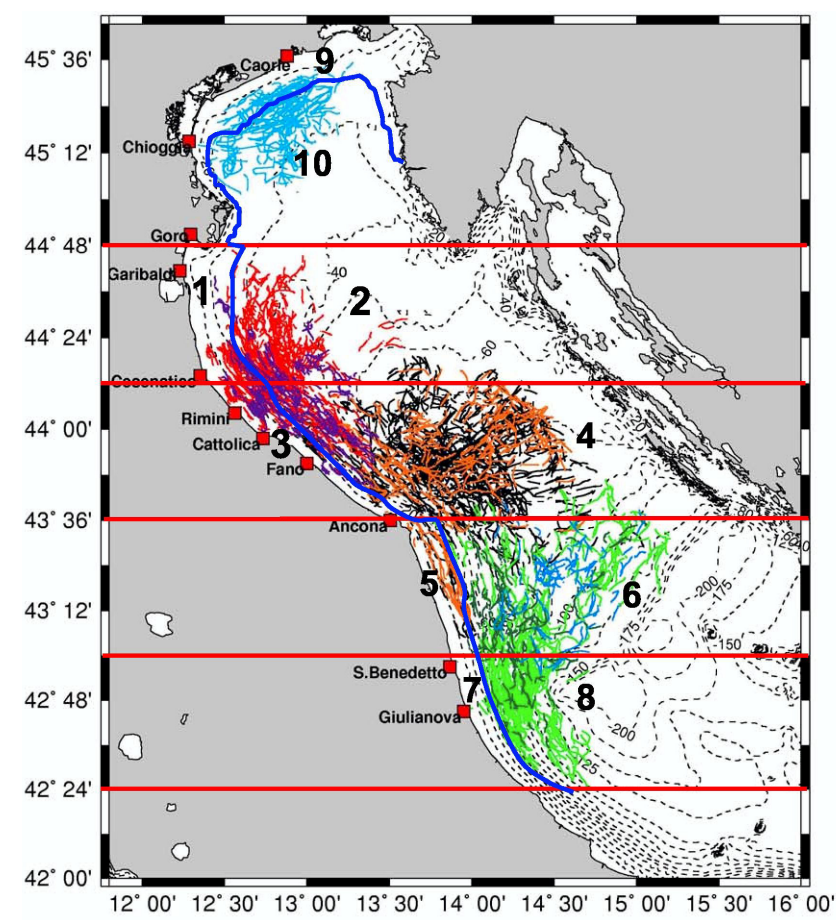

Fig. 2. Green tracks indicate the hauls carried out by the fishing vessel from Giulianova, in dark green and cyan the hauls of the two trawlers from S. Benedetto del Tronto, in black and orange the tracks of two vessels from Ancona, in purple and red the tracks of Rimini vessels and in light blue the tracks of Chioggia vessels. The areas (labelled from 1 to 10) used in the CPUE standardization processes are shown.

on, the GPS is as well and GPS records are stored every time catch records are. Position accuracy is about $20 \mathrm{~m}$. Position, date, time and speed are recorded every minute. Catch data are stored in a different file with respect to the file containing position records. At this stage catches are not geo-referenced yet as catch data could be inputted after the haul is concluded far from the real position. Haul selection and then catch georeferencing is accomplished in the post processing phase.

\subsubsection{Temperature and pressure recorder}

The third component of the FOS is a temperature and pressure sensor (TPs hereafter Fig. 1). The probe used is produced by Star Oddi company (Iceland) and its main characteristic is its reduced dimension. This characteristic is important for the current application in that the sensor is attached to the fishing gear and small equipment limits the impact on the gear and can be positioned in a safe way. The TPs used are of the DST Milli type; they are only $4 \mathrm{~cm}$ in length with a diameter of about $1 \mathrm{~cm}$. Accuracy is $\pm 0.1^{\circ} \mathrm{C}$ for temperature and $\pm 0.4 \%$ of depth range. Two different sensor ranges were used: $100 \mathrm{~m}$ and $300 \mathrm{~m}$. Memory space and also battery consumption are related to the sampling interval. The lowest value is $1 \mathrm{~s}$ and we used $30 \mathrm{~s}$ for lampara vessels and $1 \mathrm{~min}$ for volante as a best compromise between data time resolution and memory and battery usage. Milli sensors are self contained with the possibility of being programmed to work only during periods when data collection is performed. This characteristic is particularly useful also because fishing vessels work approximately during the same hours of the day. So sampling can be continuous during working hours (even when the fishing gear is not at sea) and on stand by for the remaining time.

In order to test the performance of TPs, a comparison with a Sea Bird 911 plus probe (two order of magnitude better than TPs in accuracy) were carried out fastening the TPs at the CTD frame during some oceanographic cruise of the R/V Dalla Porta of the Italian National Research Council. Being $\Delta \mathrm{T}=\mathrm{T}_{m s}-\mathrm{T}_{\mathrm{CTD}}$, results show very good agreement between the temperature collected by Milli sensors $\left(\mathrm{T}_{m s}\right)$ and CTD $\left(\mathrm{T}_{\mathrm{CTD}}\right.$ ) especially in areas with low temperature gradients (Figs. 3a, b). $\Delta \mathrm{T} \sim 3^{\circ} \mathrm{C}$ when data are collected in areas of strong gradient such as across a summer thermocline (Figs. 3a, b). This is because the time response of the TPs is not as fast as that of the CTD, so they are unable to follow rapid thermal variations. Together with the rate of response, the descent velocity of the sensor is actually a fundamental parameter in determining the accuracy of the data. Tests to evaluate this contribution showed that when the descent velocity of the sensor was about $10 \mathrm{~m} / \mathrm{min}, \Delta \mathrm{T} \sim 2^{\circ} \mathrm{C}$ in correspondence of the thermocline, whereas $\Delta \mathrm{T} \rightarrow 0$ above and underneath the thermocline. Also TPs up-cast profile was in very good agreement with the CTD one (Fig. 3b).

TPs provide a vertical temperature profile of the water column when applied to a lampara fishing gear. In this case the vessel holds the same position for the entire haul being TPs mounted on the lowest part of the net, its vertical displacement described the vertical temperature profile of the water column. Considering that the average descent velocity of the net during a lampara haul is about $8-9 \mathrm{~m} / \mathrm{min}$ and that the thermocline forms only during few months in the Adriatic Sea, the use of these sensors was assumed to be appropriate. Volante temperature data refer essentially to the trawling path of the vessels, when the net is approximately close to the sea bottom. Data collected during lowering and rising of the fishing gear can not be considered because these operations are too fast (around $20 \mathrm{~m} / \mathrm{min}$ in both cases) for the characteristic time response of this class of TPs.

Although the performances of these sensors was satisfactory, the need to increase the accuracy of temperature measurements up to a standard oceanographic temperature recorder, required improvements of the sensors. First of all, an increase in the response rate with respect to temperature variations; secondly the use of a pressure dependent trigger to switch on the sensor; thirdly an increase in memory space (allowing for both a faster sampling rate and a longer maintenance interval) Such improvements were carried out by Star Oddi company following our request and a new version of the 

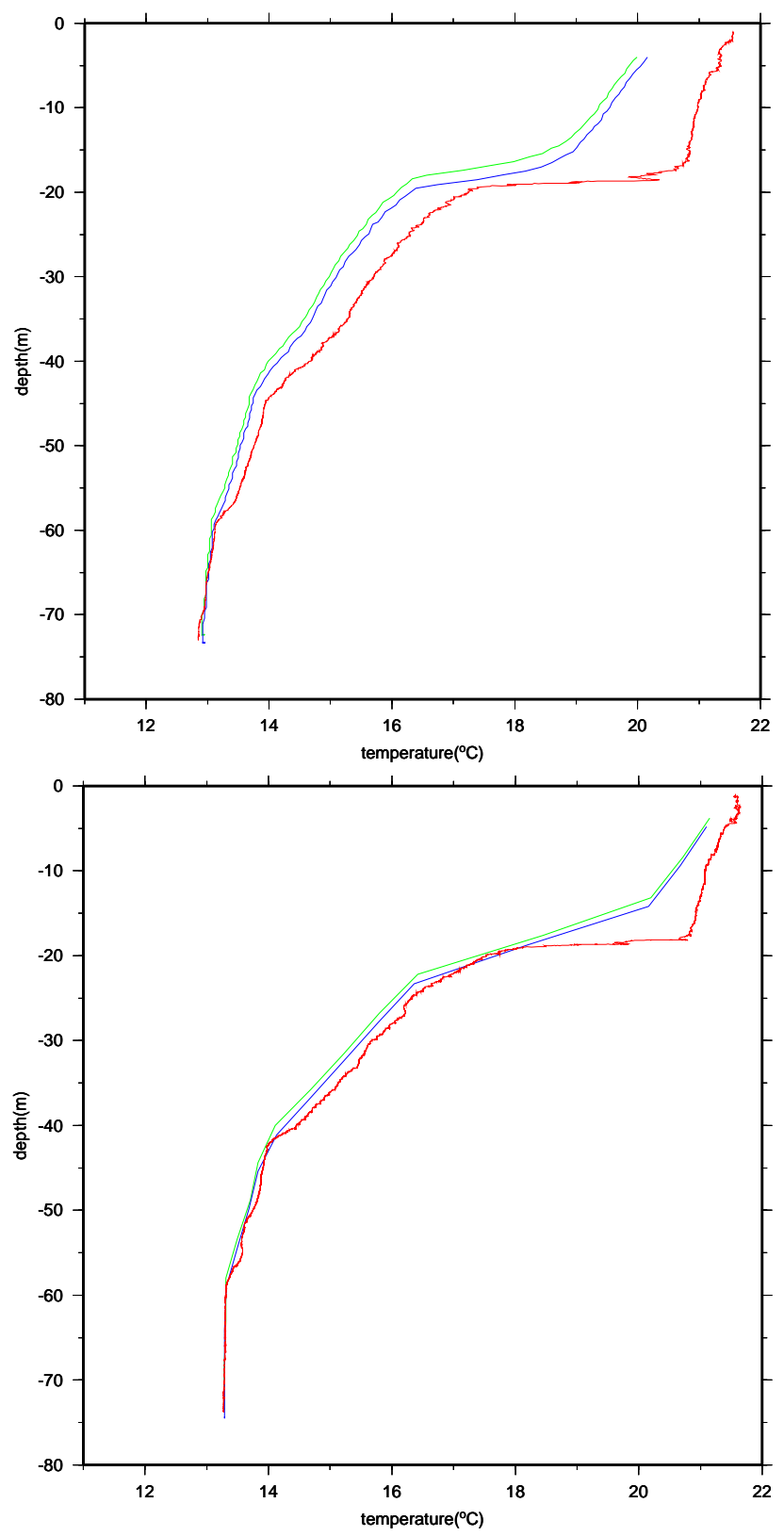

Fig. 3. Temperature profiles collected by a Sea Bird CTD (red curve) and Star Oddi Milli sensors (blue and green curve). In panel (a) Milli sensor sampling interval is $1 \mathrm{~s}$ and the descent velocity is approximately $1 \mathrm{~m} / \mathrm{s}$. In panel (b), Milli sensor sampling interval is $30 \mathrm{~s}$ and the descent velocity is approximately $10 \mathrm{~m} / \mathrm{min}$.

sensor, called DST Logic, is now available. With these new characteristics, the accuracy was increased by about the $20 \%$ in correspondence to strong temperature gradients (Figs. 4a, b). Furthermore, a higher sampling interval can be used during the haul because the Logic sensor works during the haul only and memory space is thus saved. Enlargement of memory space, allows to further increase sampling interval. Logic
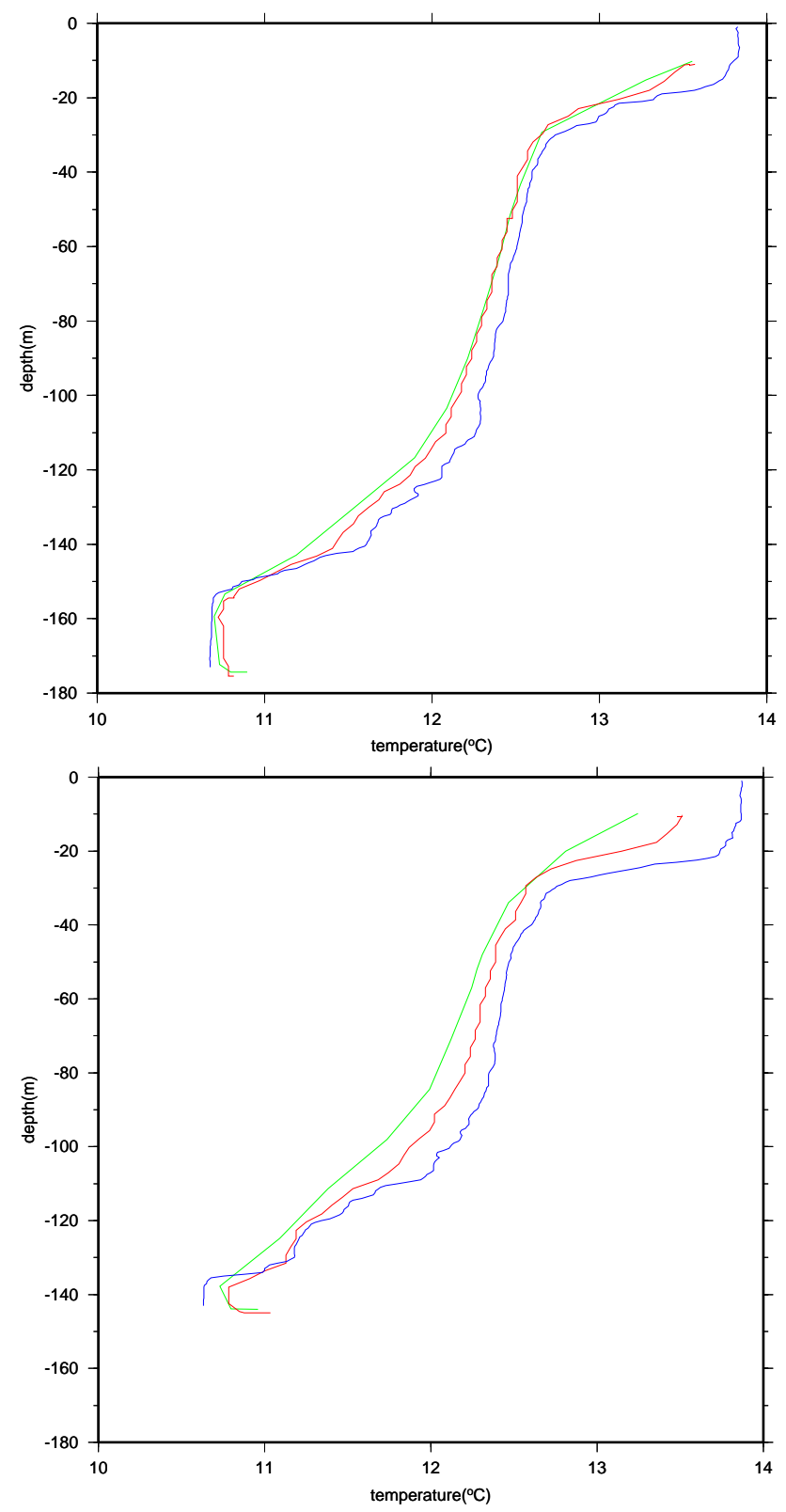

Fig. 4. Two examples of temperature profiles collected using Sea Bird CTD (red curve), Star Oddi Milli sensor (green curve) and Star Oddi Logic Sensor (blue curve).

are currently set up with a sampling interval of $1 \mathrm{~s}$ for lampara application and $5 \mathrm{~s}$ for volante.

\subsection{Data set}

\subsubsection{FOS data collation}

FOS was installed on eight boats belonging to fleets of Chioggia, Rimini, Ancona, S. Benedetto del Tronto and Giulianova degli Abruzzi, from north to south respectively 


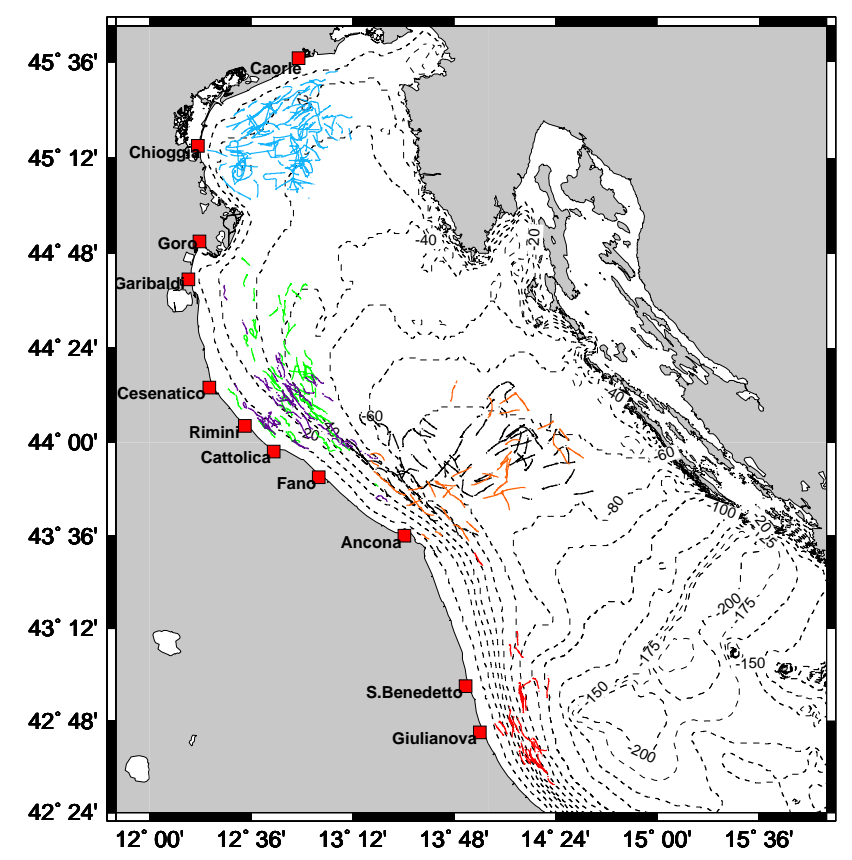

Fig. 5. An example of monthly (May 2005) pelagic trawler tracks distribution. Red tracks indicate the hauls carried out by the fishing vessel from Giulianova, in black and orange the tracks of two vessels from Ancona, in purple and green the tracks of Rimini vessels and in light blue the tracks of Chioggia vessels.

(Fig. 2). Initially the decision was to monitor the fleet of one harbour (Ancona) in order to increase the statistical relevance of the data and assuming that more vessels could guarantee a good spatial coverage. Successively, because fishing vessels of the same fleet typically operate approximately within the same fishing areas, it was assumed that one boat could be representative of the movement of the entire fleet, and the decision was taken to sample vessels belonging to fleets of different harbours (Rimini, Ancona, S. Benedetto del Tronto and Giulianova degli Abruzzi). This choice ensured a good spatial coverage at least of the middle Adriatic (Fig. 2). Four vessels were equipped with the instrumentation within the first 3 months from the beginning of data collection (August 2003). The other four were provided with a FOS a year and half later, thanks to Italian national funding of the Directorate General for Fishery of the Ministry of Agriculture. At present two vessels per harbour are monitored, with the exception of Chioggia and Giulianova (where only one vessel is monitored). Giulianova degli Abruzzi and San Benedetto del Tronto vessels change fishing gear at the end of May and until approximately mid October they are set up as lampara. For the remaining part of the year they fish as volante along with the other monitored fishing vessels.

FOS provides three different files which are uploaded on a database developed in MS Access ${ }^{\circledR}$. The uploading procedure ends with data collation: catch data are geo-referenced and associated with temperature at depth data. This operation is done for each volante and lampara haul. The selection of haul positions is based on depth data obtained by TPs. The start time of the haul is set to coincide with the lowering of the gear and the end time coincides with the lifting of the gear. All positions included in this time interval are then selected. Catch data are input sequentially and for every fishing day, there is a correspondence between the temporal sequence of catches and TPs measurement. Thus the order of the hauls and their date allow merging of daily TPs data with catch and position data. An example of a monthly tracks obtained after the geo-referencing procedure is shown in Fig. 5. While catch data covered all the period of measurement, temperature and pressure data were sometimes missing. The reasons for these failures are different: first of all in some cases the sensors were lost or damaged. Moreover, when the GPS does not receive the signal, TPs data cannot be associated with geographic position.

\subsubsection{Environmental data (from observations and numeri-} cal models)

Temperature measurements at net depth were collected during the hauls. These measurements provide a parameter generally considered important in determining fish aggregation, directly or indirectly. Many studies have pointed out the relationship between fish abundance and SST (Simpson, 1994; Cole, 1999; Waluda et al., 2001; Yanez et al., 2001), the latter being obtained by satellite measurements. Within the framework of MFSTEP, SST data and also surface chlorophyll are made available for the entire Adriatic Sea by the ISAC-CNR, Rome (http://www.bo.ingv.it/adricosm, Böhm et al., 2003) and temperature at depth data are also available as model outputs. Models also provide other important physical parameters in 3 dimensions such as salinity, which has been used as a further explanatory variable in the analysis.

In situ temperature data were used in the analysis. Model temperature data could be very useful for integration with in situ data or SST when they are not available. Figure 6 illustrates a comparison between in situ temperature data and model temperature reanalysis for the period October 2003November 2004. Data from reanalysis were not yet available following November 2004. For this comparison temperature data collected by pelagic trawlers were used. For each haul an along track average value was obtained considering only the data collected when the net was at fishing depth (that can be close to the sea bottom or at an intermediate level depending on where the fish school was detected). The haul average position was reported on the model grid and a temperature value was linearly interpolated on each haul position using the four nearest grid values. In particular data gathered by one pelagic trawler from Rimini are represented in Fig. 6 where the two curves are in good agreement except in correspondence of quick warming which occurred during the first decade of June 2004 (in Fig. 6 from haul numbers 
Table 1. Pelagic trawlers catch data information.

\begin{tabular}{lllll}
\hline Vessel & $\begin{array}{l}\text { Total number } \\
\text { of hauls }\end{array}$ & $\begin{array}{l}\text { Number and percentage } \\
\text { with T/P data }\end{array}$ & $\begin{array}{l}\text { Number and percentage } \\
\text { with catch data }\end{array}$ & $\begin{array}{l}\text { Number and percentage } \\
\text { with position data }\end{array}$ \\
\hline Ancona 1 & 1376 & $980(71 \%)$ & $1137(83 \%)$ & $820(60 \%)$ \\
Ancona 2 & 530 & $508(96 \%)$ & $447(84 \%)$ & $475(89 \%)$ \\
Chioggia & 346 & $322(93 \%)$ & $291(84 \%)$ & $314(91 \%)$ \\
Giulianova & 635 & $534(84 \%)$ & $528(83 \%)$ & $444(70 \%)$ \\
Rimini 1 & 1343 & $1131(84 \%)$ & $988(73 \%)$ & $824(62 \%)$ \\
Rimini 2 & 554 & $473(85 \%)$ & $527(95 \%)$ & $364(65 \%)$ \\
S. Benedetto 1 & 166 & $148(89 \%)$ & $131(79 \%)$ & $120(72 \%)$ \\
S. Benedetto 2 & 215 & $209(97 \%)$ & $143(66 \%)$ & $144(67 \%)$ \\
\hline
\end{tabular}

180 to 200) when model data seem to overestimate the actual temperature. After this transitioning phase, the two curves were, once again, in good agreement. This was also confirmed by regression analysis $\left(R^{2}=0.94\right)$. Mean and standard deviation of the difference between in situ and model temperatures were calculated for the first four fishing vessels used in this experiment. The mean did not exceed $0.5^{\circ} \mathrm{C}$ and the standard deviation was in the worst case about $1.5^{\circ} \mathrm{C}$.

\subsection{Evaluation of anchovy abundance}

In the present paper, data from pelagic trawlers only were considered in the analysis as they are more numerous than purse seiners, they cover a greater area and they have a longer temporal coverage. Table 1 summarises information regarding volante hauls for the period October 2003-August 2005. In particular, the total number of hauls for each vessel is reported together with the number and percentage of hauls with catch, temperature and pressure and position data.

After FOS data were collated, the next step consisted in estimating an index of relative fish abundance. To do this we followed the classical method based on the use of catch and effort data (Richards and Schnute, 1992; Goñi et al., 1999; Campbell, 2004; Santojanni et al., 2005). MFSTEP satellite and model products were selected and used as explanatory variables.

Catch/abundance relationship is expressed by the equation:

$C=q E D$

where $D$ indicates the fish density, $q$ is the catchability coefficient and $E$ is the fishing effort. The fishing effort can be defined as the sum of means deployed for catching fish in a defined area over a defined period of time (Annex $\mathrm{V}$ of SEC (90)2244 Commission Communication to the Council and Parliament of the European Communities on the Common Fisheries Policy). Basically fishing effort comprises two capacity elements (vessel and gear) and an activity measure (time); thus it can be affected by either of these components. Catchability, as effort, depends on technical parameters but

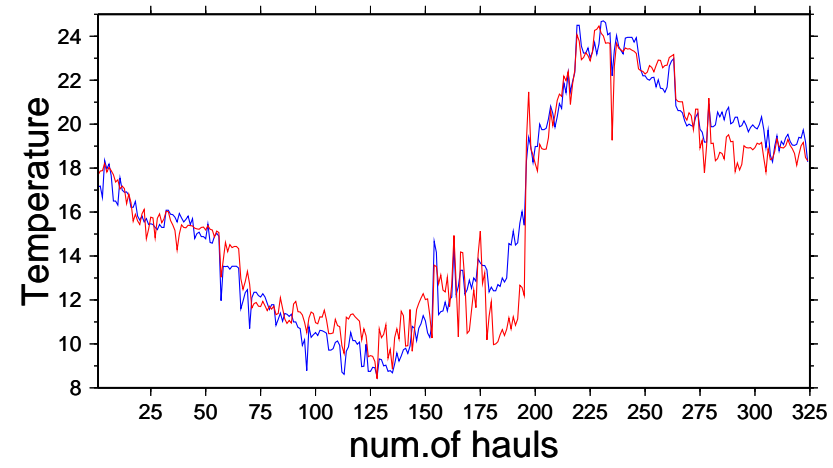

Fig. 6. Comparison between in situ temperature measured during Rimini trawler hauls (red curve) and re-analysis temperature obtained from MFSTEP numerical models (blue curve).

also on biological factors such as fish availability and behaviour during fishing activity. From a statistical point of view it can be considered as the probability of any single fish to be caught. The Catch per unit of Effort CPUE is given by the ratio:

CPUE $=\frac{C}{E}=q D$.

If $D$ is expressed in terms of number of fish $N$ over the fishing ground area A, then Eq. (2) can be rewritten as:

$\mathrm{CPUE}=\frac{C}{E}=\frac{q N}{A}$.

CPUE is thus a function of the coefficient $q$ and of the number of fish. If the variations of $q$ can be accounted for, CPUE depends on the number of fish $N$ only. A correct evaluation of $q$ is thus crucial in order to use catch rate as an index of abundance. Catchability $(q)$ depends on many variables which are not constant in time and space, and also vary for different fishing vessels. The typical way to account for these factors is to remove their effects on catch rates. This process is known as catch and effort standardization (Richards and Schnute, 1992; Goñi et al., 1999; Campbell, 2004; Maunder and Punt, 2004; Santojanni et al., 2005). Formally, all 
the effects are represented by a multiplicative model. Considering a fishing vessel $\mathrm{A}$, the model relates the catch rate of $A$ to the catch rate of a reference vessel and also it has to account for the difference between the current and standard vessel in terms of fishing power, area effects, time spent at sea and other possible factors. The reference vessel can be one of those monitored and a well accepted method to determine the proportional coefficients consists in using Generalized Linear Modelling (GLM) (Hilborn and Walters, 1992; Venables and Dichmont, 2004). This procedure provides an indication of the relative importance of the factors influencing catch rates and the computation of the standardized abundance index as well.

In order to evaluate the standardized CPUE from our catch data one of the two pelagic trawlers from Ancona was chosen as reference vessel unit. A first explanatory variable of the model accounts for the difference in fishing power between vessels. Fish abundance is not constant in time, thus an independent variable representing time variation was introduced. The spatial variability of abundance was represented through a variable Area. As shown in Fig. 2, the domain was divided into 10 areas: 5 further inshore and 5 offshore. The isobaths marked in blue in Fig. 2 represent the limit between the inshore and offshore areas, while the areas are separated in latitudinal sense every 0.6 deg from $42.2 \mathrm{~N}$ to $44.8 \mathrm{~N}$ and the northernmost sector of the Adriatic (the Gulf of Trieste) was considered in its entirety. Following initial attempts at using all data available, data collected by the Chioggia trawler were discarded in order to prevent problems related to collinearity because no possibility of overlapping with other vessels existed. Catches obtained in the southernmost sector of the domain (basically the area of S. Benedetto del Tronto and Giulianova) are characterized by a lower number of boxes of larger individuals than catches obtained in the northern sector (Rimini and Chioggia areas). Ancona fishing vessels can overlap on both the fishing grounds and also operate on an exclusive area. In this case, catch and size have an intermediate value between northern and southern values. Thus a further independent variable was introduced to account, in particular, for differences in mean size of individuals in the catch (the number of boxes being to some extent a consequence of the size of anchovy caught). Three size classes were chosen: the first including all catches with sizes lower than 55 anchovies $/ \mathrm{kg}$; the second class ranging between 55 and 70; the third including catches with more than 70 anchovies $/ \mathrm{kg}$. The first class was thus characterized by the biggest anchovies.

\subsection{Generalized Additive Models (GAM)}

Generalized additive models are suitable tools for exploring a data set and pointing out relationships between dependent and independent variables (Hastie and Tibshirani, 1991). GAM have already been used in spatio-temporal stock assessment modelling of different marine species (Swartzman et al., 1992; Daskalov, 1999; Hedger et al., 2004), as well as to carry out temporal analysis of commercial trawler data (Denis et al., 2002) or to improve catch-at-age indices of target species (Piet, 2002). GAM were also proposed as one possible comparison standards for catch data obtained from commercial logbooks (Walsh and Kleiber, 2004).

GAM are more flexible tools than traditional parametric models (such as linear or nonlinear regression) in that some parametric assumptions are relaxed, allowing to uncover patterns in the relationships between the dependent variables and independent variables that could otherwise be missed.

Let $\mathrm{Y}=\left(y_{1}, \ldots . . y_{p}\right)$ be the response variable and $\mathrm{X}=\left(x_{1}, \ldots \ldots, x_{p}\right)$ be a set of predictor variables. The linear relationship between expected value of $\mathrm{Y}$ and $\mathrm{X}$, assumes the form:

$$
\boldsymbol{E}(\boldsymbol{Y})=\boldsymbol{f}\left(\boldsymbol{x}_{1}, \ldots, \boldsymbol{x}_{p}\right)=\beta_{0}+\beta_{1} \boldsymbol{x}_{1}+\ldots+\beta_{p} \boldsymbol{x}_{p}
$$

Additive models generalize linear models by substituting the $\beta$ parameters in Eq. (4) with smoothing functions. In this case, if $s_{1}, \ldots ., s_{p}$ are the smoothing functions, the expectation $\mathrm{Y}$ can be written as:

$$
E(\boldsymbol{Y})=\boldsymbol{f}\left(x_{1}, \ldots, x_{p}\right)=s_{0}+s_{1} x_{1}+\ldots+s_{p} x_{p}
$$

The $s$ functions are local smoothers and are estimated in a nonparametric way. Spline functions are commonly used to represent the smoothing terms.

GAM extend linear models in another way, namely by allowing for a link between $f\left(x_{1}, \ldots . ., x_{p}\right)$ and the expected value of the dependent variable. In this way an alternative distribution for the underlying variation can be considered and not just normal distribution. There are many statistical applications where Gaussian models can not be used allowing GAM to be applied to a wide range of case studies. GAM consist of a random component, an additive component, and a link function relating first two components. The response $Y$ is the random component and it is assumed to have a density in the exponential family:

$$
f_{Y}(\boldsymbol{y} ; \theta ; \phi)=\exp \left[\frac{\boldsymbol{y} \theta-\boldsymbol{b}(\theta)}{\boldsymbol{a}(\phi)}+\boldsymbol{c}(\boldsymbol{y}, \phi)\right]
$$

where $\theta$ is called the natural parameter and $\phi$ is the scale parameter. Normal, binomial, and Poisson distributions are all included in this family, together with others. The additive component can be written as:

$\eta=s_{0}+\sum_{i=1}^{p} s_{i}\left(X_{i}\right)$

where $s_{1}, \ldots . ., s_{p}$ are the smoothing functions. Eventually, the link function $g$ defines the relationship between the mean $\mu$ of the response variable and $\eta$. In general this link can be expressed by the relation $g(\mu)=\eta$ whereas the most popular link function is the canonical link by which $\mu=\eta$.

Generalized linear models are particularly useful when exploration of the data set and visualisation of the relationship 


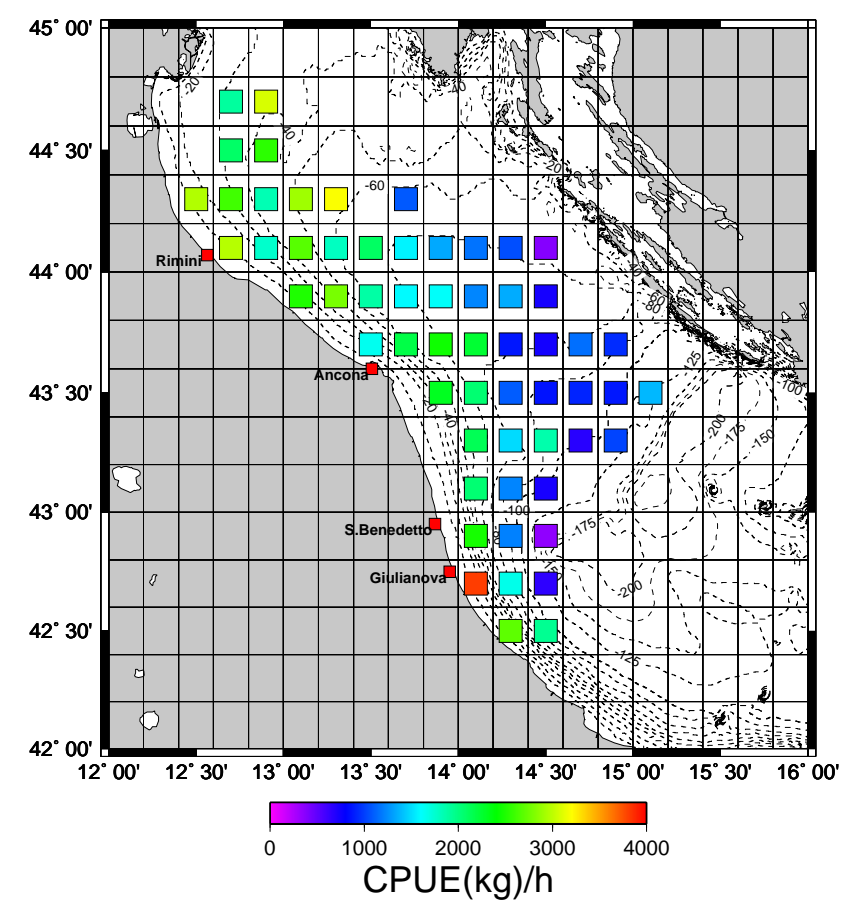

Fig. 7. Spatial distribution of standardized CPUE.

between the dependent variable and the independent variables are of concern. Where conventional linear techniques failed to describe a possible relationship, GAM can be used because of their capability to model non-linearities by means of smoothing functions. The price to pay to be more flexible than linear models is twofold: a reduced possibility of performing statistical inference and the increase in the number of degrees of freedom used by the smoothing terms.

The goodness of the fit is estimated by means of the deviance. Technically it is defined as "likelihood ratio statistic for testing any specific model within the saturated model (a model with as many parameters as there are observations), assuming the scale parameter is known and has the value 1" (Venables and Dichmont, 2004). For the normal case the relation to evaluate the deviance is the same as the residual sum of squares. Then for identity link its distribution is proportional to the chi-squared.

\section{Results}

\subsection{Catch per unit of effort distribution}

General linear models (GLM) were applied in order to derive a standardized value of CPUE.

The duration of the hauls was highly variable, so in order to render each single haul catch value comparable with the others, an hourly catch value was calculated and transformed to $\mathrm{Kg}$.

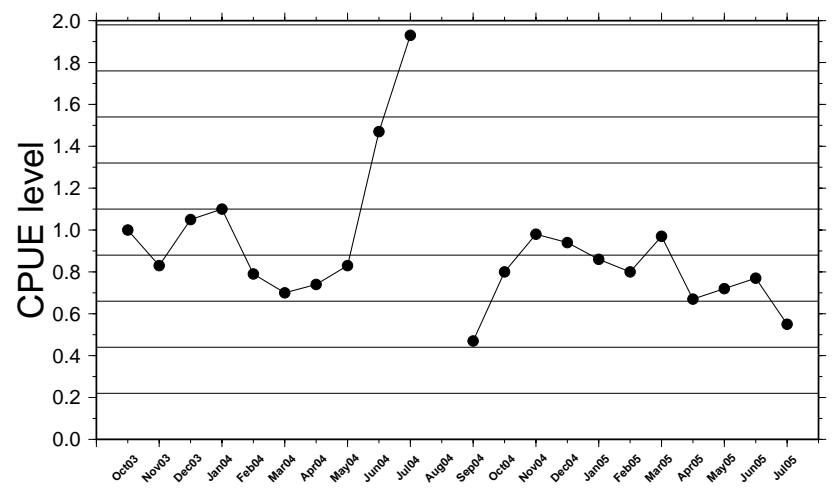

Fig. 8. Monthly standardized CPUE time series.

For each haul a standardized value of CPUE was calculated and used in the analysis. The a-temporal representation of the distribution of CPUE is shown in Fig. 7. The domain was divided in square cells of $0.2^{\circ} \times 0.2^{\circ}$. This choice ensured a good compromise between spatial resolution and statistical reliability. An average CPUE value was then computed for each cell along with the corresponding rms value (not shown here). Highest values of CPUE were found in the northernmost sector of the domain and moving southward, along a coastal band that could remind the path of the Western Adriatic Coastal Current and the underlying Dense Water Outflow Current (WACC - Cushman-Roisin et al., 2001).

Besides a temporally and spatially averaged distribution of CPUE, a monthly mean value was also evaluated. This information is important in order to detect a possible trend in abundance. In particular, the exponential values obtained from the GLM analysis for the time variable, are represented in Fig. 8. The first month of observation (October 2003) was considered as reference point, so its value is set to 1 and all the other values were referred to it. Furthermore, the difference between the current and the reference value provides the abundance increase or decrease in percentage. The CPUE monthly mean curve shows a strong increase starting from June 2004 to the end of July 2004. The reason for this behaviour is not so clear especially if compared with the same month in 2005 when abundance was less than half. This may be an artefact introduced by the computation of CPUE considering that the number of observations used to evaluate CPUE in June and July 2004 were the lowest. A decrease was revealed in September 2004 (generally, in the Adriatic Sea, trawler activity is interrupted during the month of August) followed by a recovery in the subsequent two months. A weak descending trend can be observed between November 2004 and July 2005 At present it is wise to skip any speculation about the reasons of such behaviour and wait for more observations which will allow a better comprehension. 

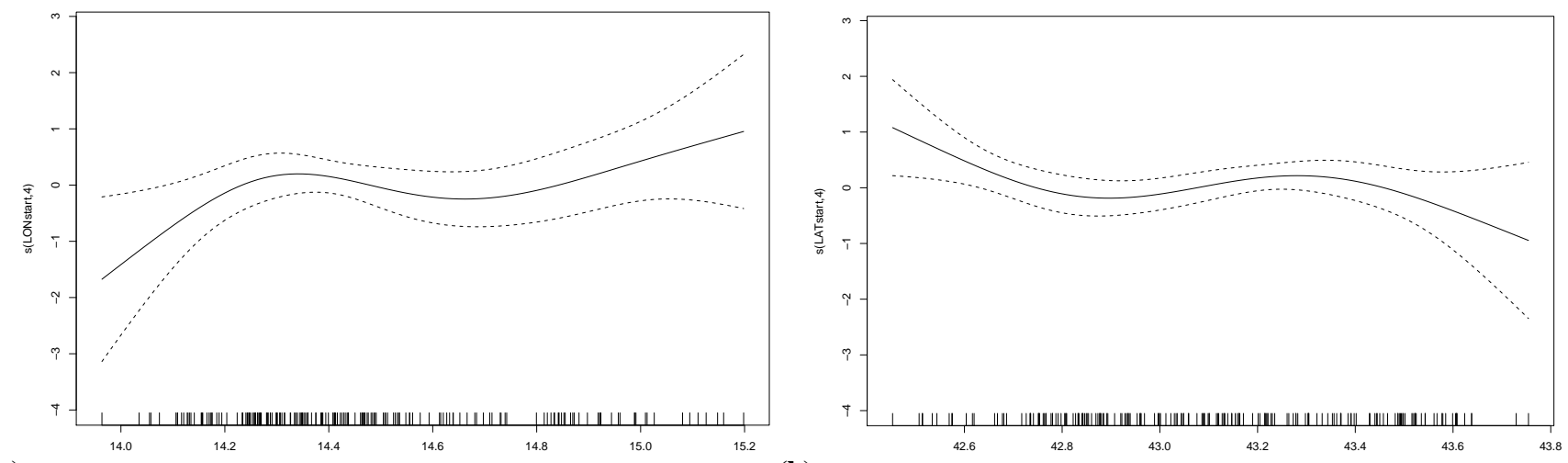

(a)

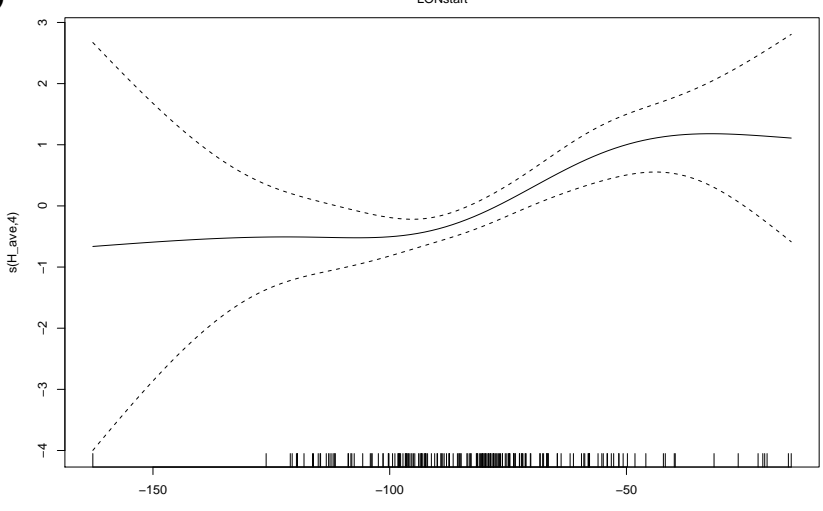

(c)

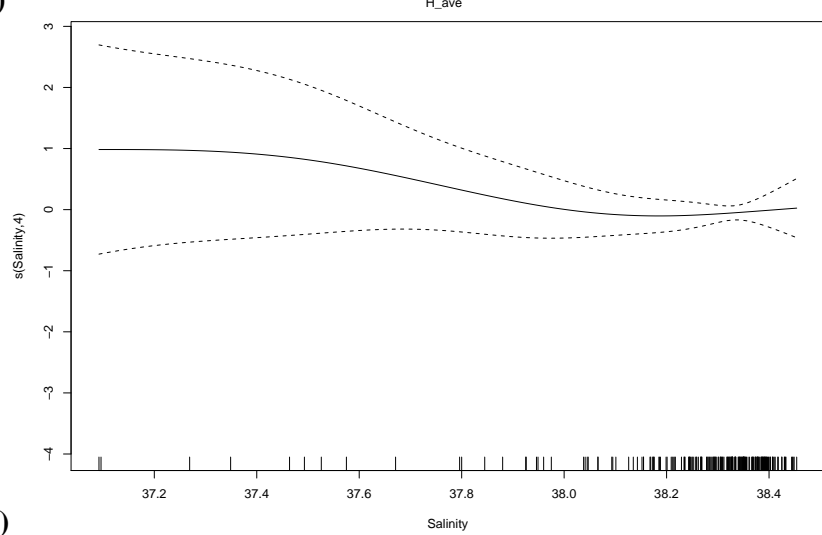

(b)

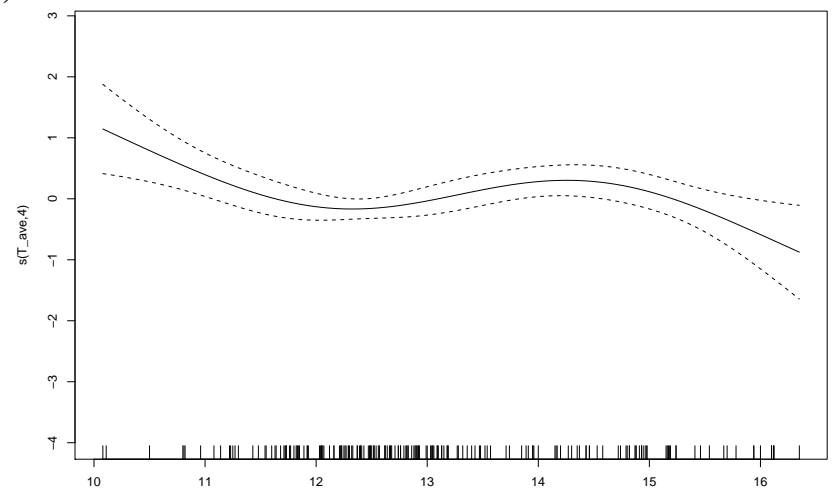

(d)

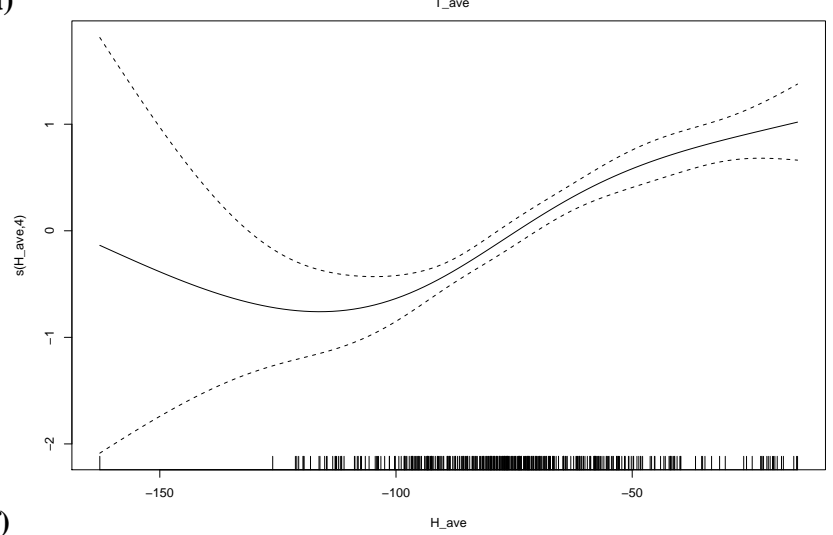

Fig. 9. Relationship between longitude (a), latitude (b), depth (c), temperature (d) and salinity (e) and abundance obtained applying GAM (Model 2) to Giulianova data set. In the last panel (f) the effects of depth on abundance data obtained applying Model 1 are represented.

\subsection{GAM explanatory analysis}

Standardized CPUE values were analysed to find possible relationships with environmental parameters. Some environmental parameters were available as model outputs and others as in situ measurements. Position, depth, temperature and salinity were chosen for GAM applications. The first four parameters are FOS products whilst salinity is a model output. In particular salinity re-analysis data, which were available from March 2001 to November 2004, were used; therefore for this application salinity data are available for the period October 2003-November 2004. Remote sensing data cannot be used at this stage of the analysis because of there are too many hauls without measurement and GAM require great spatial and temporal coverage. Separate considerations regarding relationships of satellite products and abundance will be made in the next paragraph. GAM were applied to three vessels: in particular one vessel from Ancona and one from Rimini because they had the longest and most continuous time series. Although the Giulianova vessel switched fishing gear (to lampara) for about 5 months, for the remaining part of the year (7 months) it had the most continuous 


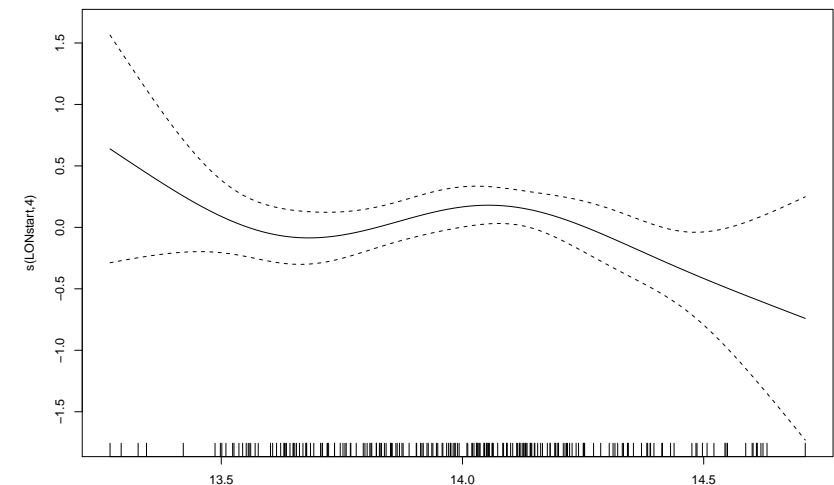

(a)

LoNstart

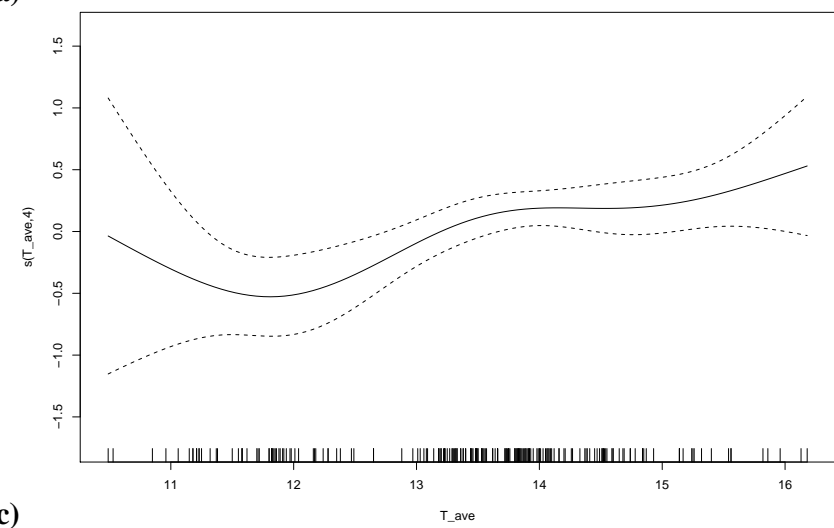

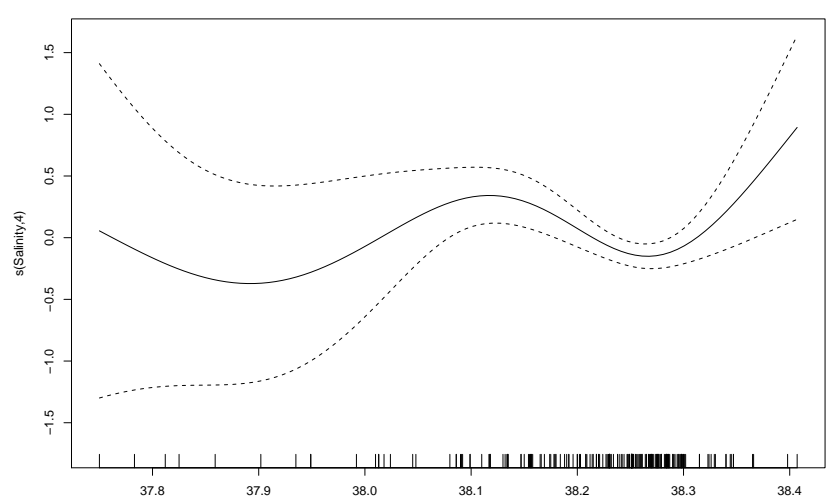

(b)

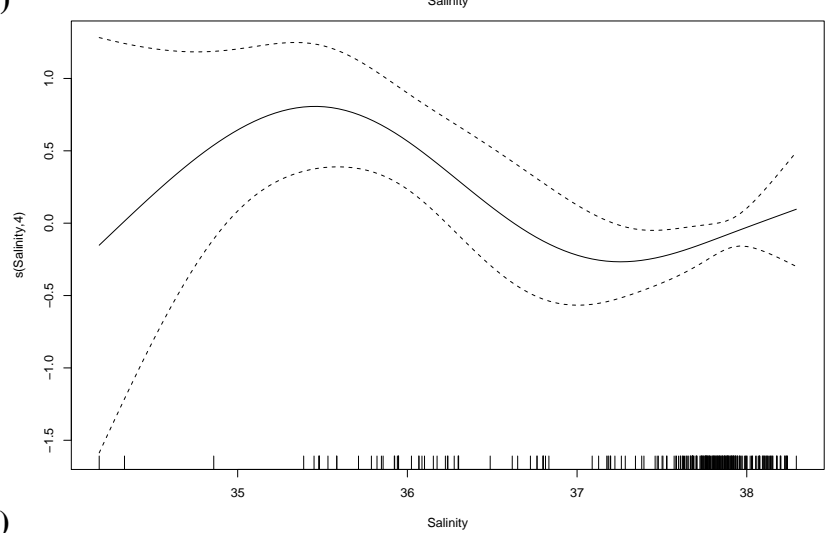

Fig. 10. Relationships between longitude (a), salinity (b) and temperature (c) on abundance applying GAM to the Ancona data set. In panel (d) effects of salinity on abundance for the case study of Rimini are shown. This result was obtained applying GAM with temperature and salinity as explanatory variables only.

catch time series. For this reason we included data coming from this vessel in the analysis.

Along with information about possible relationships between dependent and independent variables, GAM also provide information as to which could be the optimal set of explanatory variables. To do this, the Akaike's information criterion was used (AIC).

Different models were set up in order to find the optimal set of explanatory variables. Among these models, three main cases were chosen. In model 1 only FOS data were used, thus position, depth and temperature. This was also the application with the complete series of catch data (October 2003-August 2005). In model 2, salinity was introduced and the time series limited to November 2004 as in model 3, where position data were discarded and only depth, temperature and salinity were used. The size of data set used has effects on the AIC value, so this aspect has to be borne in mind during the discussion following.

No conclusive results were found and a complex scenario appeared. The best result (in terms of both deviance explained and AIC value, see Table 2) was obtained for the Giulianova data set using all the independent variables in the GAM application (Model 2). The effects of the explanatory variables on abundance are represented for this case in Fig. 9. Abundance appears to increase eastwards and southwards. This is in contrast with the indications derived from depth and salinity plots where the increase in abundance was found in correspondence with decreasing depth and salinity. Of course the latter two variables are correlated thus collinearity problems may arise. On the other hand, the deviance explained by model 1 (without salinity) was lower and AIC is greater than in model 2. Thus the decision was taken to keep salinity (or depth) in the analysis. Figure $9 \mathrm{f}$ reveals a stronger relationship between depth and abundance in model 1 compared to model 2. Only depth, temperature and salinity were used in model 3. AIC was higher (but the number of observations lower) than in model 1 and the explained deviance was only a little bit lower than in the model 2 application.

GAM application on the data set of the vessel of Ancona yielded less information compared to the previous case. Model 2, again, explained a higher percentage of deviance but it had the highest AIC.

In this case, acceptable results were given by a fourth combination of independent variables. Using longitude, temperature and salinity, AIC was 1233 and the deviance explained about $20 \%$. The effects of the three variables on abundance 
Table 2. Comparison of three GAM applications. Explanatory variables used are for the application of Ancona (AN) and they are the same for the other two cases of Giulianova (GIU) and Rimini (RIM).

\begin{tabular}{llll}
\hline Model & AIC & $\begin{array}{l}\text { Deviance } \\
\text { explained }\end{array}$ & DF \\
\hline AN-Model 1 (lon,lat,temp,depth) & 1068 & $20 \%$ & 17 \\
AN-Model 2 (lon,lat,temp,depth, sal) & 1279 & $23 \%$ & 21 \\
AN-Model 3 (depth,temp,sal) & 1273 & $17 \%$ & 13 \\
GIU-Model 1 & 1117 & $33 \%$ & 17 \\
GIU-Model 2 & 1003 & $45 \%$ & 21 \\
GIU-Model 3 & 1055 & $37 \%$ & 13 \\
& & & \\
RIM-Model 1 & 1549 & $8 \%$ & 17 \\
RIM-Model 2 & 1657 & $22 \%$ & 21 \\
RIM-Model 3 & 1627 & $17 \%$ & 13 \\
\hline
\end{tabular}

are shown in Figs. 10a, b, c. A weak increase in abundance occurred in correspondence with high temperature and salinity values and moving westwards (near the coast). As before, the two latter results are in contrast.

The situation is more confused in Rimini. Model 1 explained only $8 \%$ of the deviance. Introducing salinity, the value jumped to the $22 \%$ (approximately the same value as Ancona). When a model including only temperature and salinity as explanatory variables was used, the salinity vs. abundance plot (Fig. 10d) showed a maximum in abundance at approximately $35.5 \mathrm{psu}$ to then quickly decrease. The maximum was less evident in the other GAM application. The AIC value in this case was 1622, lower than models 2 and 3.

\subsection{Preliminary satellite data analysis}

Although their contribution could be important, satellite products (SST and chlorophyll) were not used in GAM applications, because of the paucity of data. SeaWIFS chlorophyll concentration data were available up to December 2004 thus all the 2005 hauls could not be associated with this parameter. SST data were, unfortunately, missing for $52 \%$ of the hauls from Giulianova, 55\% of the hauls from Ancona and $58 \%$ of the hauls from Rimini.

Using the data available a regression analysis was carried out. SST at this stage did not appear to play any significant role in driving fish aggregation. Chlorophyll behaved approximately in the same way with the exception of Giulianova abundance data. In this case the $\mathrm{R}^{2}$ was 0.49 and the correlation was statistically significant (t-test, $\mathrm{p}>0.01$ ).

\section{Discussion}

Factors influencing small pelagic fish aggregation include spawning, feeding, migration and environmental effects (Agostini and Bakun, 2002). Studies regarding how environmental conditions influence distribution and abundance of small pelagics pointed out that temperature could be an important factor (Yáñez et al., 2001; Beare et al., 2004) but salinity (Regner, 1996), currents (Nishimoto and Washburn, 2002), wind as an upwelling driving force (Cole, 1999) and eventually lunar effects (Agenbag et al., 2003) could play some roles in driving aggregation. Understanding how the environment influences fish distribution is complicated. The complexity of the problem is not only conceptual but also related to the lack of data to describe the environment and fish distribution at a comparable spatial and temporal resolution. Estimates of fish biomass and distribution are generally obtained from experimental scientific surveys, which are limited in time and sometimes in space too. Standard population dynamics assessment methods based on commercial data (e.g. Virtual Popolation Analysis - VPA, Hilborn and Walters, 1992) do not give any information on fish distribution but only on biomass and exploitation levels. The FOS is trying to bridge these gaps because a time continuous picture of fish abundance distribution is obtained by means of georeferenced abundance indices (CPUE), which can be then used together with detailed sets of environmental descriptors obtained both from models and in situ measurement in the framework of the MFSTEP project. Moreover this CPUE index could provide a near real time monitoring of the state of the stock. Temperature data collected by fishing vessels, can be used in numerical circulation models. Thus the possibility of collecting oceanographic data using fishing vessels should be given greater consideration in the future. Fishing vessels spend about 200 days at sea covering all the seasons and approximately the same area, at least on a yearly cycle.

At present the limits of the system are essentially two: firstly, the application of the FOS is subject to the willingness of the fishermen; hence it is necessary to strengthen the relationships with the fishery sector. Secondly, at present FOS data are available approximately monthly. This time interval could be enough for fishery management purposes but is too wide for operational applications. Forecasting of the marine environment is accomplished daily, thus the necessity to recover data at the same time interval is mandatory. Data stored in the EL can be readily sent to a remote PC by means of a GPRS modem (Fig. 1) whilst TPs need to be downloaded by hand. Pressure data are fundamental to select hauls and for catch geo-referencing. Thus in order to overcome this problem, TPs data should be transmitted to the EL. TPs with an embedded wireless transmission module included are under experimentation (e.g. by Rubec et al., 2005) but are probably too big and impacting to be used on commercial fishing vessels. The possibility of developing a compact TP (and possibly a CTD) probe including a transmission wireless module 
will be an important issue to investigate in the near future.

Preliminary results of our study would suggest that the oceanographic features which determine abundance distribution are more easily detected in the area of Giulianova, probably to particular dynamics which may be more favourable to fish aggregation. In fact the coastal dynamics south of Ancona is characterised by a particularly intense WACC in turn characterised by high levels of kinetic energy (CushmanRoisin et al., 2001; Poulain, 2001). Areas of convergence could be found both where the WACC encounters the descending branch of the Middle Adriatic gyre and in correspondence of the frontal zone which separates the coastal fresh waters from offshore saltier waters. Bottom topography can be also an important factor in determining areas of strong gradients such as shelf break fronts (Garcia and Palomera, 1996). Such conditions may enhance fish aggregation in the Giulianova area (central Adriatic) but the actual role of the skipper, in using his own knowledge to choose the best fishing area as a function of environmental conditions, is still unclear. Despite being scarce and thus not included in previous discussions, data collected by the S. Benedetto fishing vessel (whose main fishing grounds are the same as the Giulianova vessel), when analysed with GAM-model 2, yielded similar results (deviance explained 46\%, lowest AIC). Furthermore there is a statistically significant linear relationship between satellite derived chlorophyll and CPUE in this sector of the domain. Results obtained from data from Ancona and Rimini are more confused. The Adriatic Sea is a semienclosed basin where the contribution of the Po River outflow strongly influences both the physics and the biology of the environment. The importance of the correlation between anchovy abundance and recruitment with river freshwater output has already been proved by previous studies (e.g. Lloret al., 2004; Santojanni et al., 2006) and river effects can be also noticeable in semi-enclosed basins (Daskalov, 1999). In order to analyse the relationship between CPUE and river discharge, the spreading of fresh water and the location of haline fronts, the spatial and temporal resolution of CPUE data should probably be different, and greater, compared to that used in the present study.

Remote sensing data could provide more information in this direction. Unfortunately these were not used in GAM analyses because the percentage of hauls for which satellite data was available was low. Nevertheless, satellite products are important and work should be done towards the integration of satellite date into the set of explanatory variables. Furthermore, efforts should also be made towards a similar integration of data emerging from bio-chemical models. Together these integrations could contribute very important elements towards the understanding of anchovy distribution and reduce the uncertainty around the mechanisms which link physical and biological processes.

Lampara data were not used to evaluate the CPUE index and because pelagic trawlers stop their activity during August, no information is available for this month. Lamparas work essentially in the southern sector of the domain and including these catch data would allow to fill the exiting gaps in CPUE time series, at least for this sector of the domain. The question of how standardized CPUE are to be derived from the same vessels using different fishing gear during different periods is an interesting issue and will be focussed upon in the near future.

Forecasting fish abundance is, at present, a difficult and challenging activity. The inclusion of a component which also provides resource estimates into numerical models for environmental prediction, has not yet been achieved. Model data can be used to provide and/or integrate experimental data in order to study the relationships between resource patterns and the environment. In this context a resource observing system has to provide data with a spatial and temporal resolution comparable with model outputs. FOS discussed so far is a first and successful attempt towards this. It could be applied to other areas of the Mediterranean Sea where fishing activity is important, in order to create a wider monitoring system. Interactions and a stronger link between the research community and the fishing industry (Simpson, 1994) as well as regulatory authorities, would be a first and consistent step towards the institution of an operational fishery oceanography framework aiming towards a better management of the resources.

Acknowledgements. This work was carried out within the framework of the Mediterranean Forecasting System: Toward an Environmental Prediction (MFSTEP) activities, project funded by the European Commission V Framework Program: Energy, Environment and Sustainable Development and also supported by a national program founded by the Italian Ministry of Agriculture.

The authors would like to acknowledge G. Giannetti, B. Morello, M. La Mesa and D. Flocco for valuable discussions The authors would like to acknowledge also M. Loprejato for the valuable help given to check the correct working of the database and E. Paschini for the CTD data comparison.

GAM analysis were carried out using R software (R Development Core Team, 2004). Generic Mapping Tools (Wessell and Smith, 1991) were used to produce maps.

Edited by: N. Pinardi

\section{References}

Agenbag, J. J., Richardson, A. J., Demarcq, H., Fréon, P., Weeks, S., and Shillington, F. A.: Relating local abundance of South African pelagic fish species to environmental variables using generalized additive and linear models, Progr. in Oceanogr., 59, 275-300, 2003.

Agostini, V. N. and Bakun, A.: Ocean triads' in the Mediterranean Sea: physical mechanisms potentially structuring reproductive habitat suitability (with example application to European anchovy, Engraulis encrasicolus), Fish. Oceanogr., 11(3), 129$142,2002$. 
Attril, M. J. and Power, M.: Climatic influence on a marine fish assemblage, Nature, 417, 275-278, 2002.

Beare, D., Burns, F., Jones, E., Peach, K., Portilla, E., Greig, T., McKenzie, E., and Reid, D.: An increase in the abundance of anchovies and sardines in the north-western North Sea since 1995, Global Change Biol., 10, 1209-1213, 2004.

Beverton, R. J. H. and Holt, S. J.: On the dynamics of exploited fish population, Fish. Invest. Ser., 2, 533, 1957 (Reprint 1993).

Böhm, E., Banzon, V., D’Acunzo, E., D’Ortenzio, F., and Santoleri, R.: Adriatic Sea surface temperature and ocean colour variability during the MFSPP, Ann. Geophys., 21, 137-149, 2003, http://www.ann-geophys.net/21/137/2003/.

Campbell, R. A.: CPUE standardisation and the construction of indices of stock abundance in a spatially varying fishery using general linear models, Fish. Res., 70, 209-227, 2004

Cingolani, N., Santojanni, A., Arneri, E., Belardinelli, A., Colella, S., Donato, F., Giannetti, G., Sinovcic, G., and Zorica, B.: Anchovy (Engraulis encrasicolus, L.) stock assessment in the Adriatic Sea: 1975-2003, 2004, Paper presented at the GFCM-SAC Working Group on Small Pelagic Species, 2004.

Cole, J.: Environmental conditions, satellite imagery, and clupeoid recruitment in the northern Benguela upwelling system, Fish. Oceanogr., 8(1), 25-38, 1999.

Cushing, D. H.: Toward a science of recruitment in fish populations, Oldendorf/Luhe, pp. 175, 1996.

Cushman-Roisin, B., Gacic, M., Poulain, P. M., and Artegiani, A.: Physical Oceanography of the Adriatic Sea. Past, present and future, Kluwer Academic Publishers, Dordrecht, The Netherlands, 2001.

Daskalov, G.: Relating fish recruitment to stock biomass and physical environment in the Black Sea using generalized additive models, Fish. Res., 41, 1-23, 1999.

Denis, V., Lejeune, J., and Robin, J. P.: Spatio-temporal analysis of the commercial trawler data using general additive models: patterns of Loliginid squid abundance in the north-east Atlantic, ICES J. Mar. Sci., 59, 633-648, 2002.

Garcia, A. and Palomera, I.: Anchovy early life history and its relation to surrounding environment in the Western Mediterranean basin, Sci. Mar., 60 (supl.2), 155-166, 1996.

Goñi, R., Alvarez, F., and Adlerstein, S.: Application of generalized linear model to catch rate analysis of Western Mediterranean fisheries: the Castellón trawl fleet as a case study, Fish. Res, 42, 291-302, 1999.

Hastie, T. and Tibshirani, R.: Generalized Additive Models, Chapman \& Hall, London, 1990.

Hedger, R., Mckenzie, E., Heath, M., Wright, P., Scott, B., Gallego, A., and Andrews, J.: Analysis of the spatial distribution of mature code (Gadus morhua) and haddock (Melanogrammus aeglefinus) abundance in the North Sea (1980-1999) using generalized additive models, Fish. Res., 70, 17-25, 2004.

Hilborn, R. and Walters, C. J.: Quantitative Fishieries Stock Assessment, Choice, Dynamics and Uncertainty, Chapman \& Hall, London, 1992.

Klyashtorin, L. B.: Climate change and long term fluctuations of commercial catches. The possibility of forecasting, FAO Fish. Tech. Pap., 2001.

LLoret, J., Palomera, I., Salat, J., and Sole, I.: Impact of freshwater input and wind on landings of anchovy (Engraulis encrasicolus) and sardine (Sardina pilcardus) in shelf waters surrounding the Ebre (Ebro) River delta (north-western Mediterranean), Fish. Oceanogr., 13(1), 1-9, 2004.

Mann, K. H.: Physical oceanography, food chains, and fish stocks: a review, J. Mar. Sci., 50, 105-119, 1993.

Maunders, M. N. and Punt, A. E.: Standardizing catch effort data: a review of recent approach, Fish. Res., 70, 141-159, 2004.

Nishimoto, M. M. and Washburn, L.: Patterns of coastal eddy circulation and abundance of pelagic juvenile fish in the Santa Barbara Channel, California, USA, Mar. Ecol. Prog. Ser., 241, 183-199, 2002.

Pauly, D., Christensen, V., Guénette, S., Pitcher, T. J., Sumaila, U. R., Walters, C. J., Watson, R., and Zeller, D.: Towards sustainability in world fisheries, Nature, 418, 689-695, 2002.

O'Brien, C. M., Fox, C. J., Planque, B., and Casey, J.: Climate variability and North Sea cod, Nature, 404, 143, 2000.

Piet, G. J.: Using external information and GAMs to improve catchat-age indices for North Sea plaice and sole, ICES J. Mar. Sci., 59, 624-632, 2002.

Poulain, P. M.: Adriatic Sea surface circulations derived from drifter data between1990 and 1999, J. Mar. Syst., 29(1-4), 3-32, 2001.

R Development Core Team, R: A language and environment for statistical computing. R Foundation for Statistical Computing, ISBN 3-900051-07-0, URL http://www.R-project.org, Vienna, 2004.

Regner, S.: Effects of environmental changes on early stages and reproduction of anchovy in the Adriatic Sea, Sci. Mar., 60 (Suppl 2), 167-177, 1996.

Richards, L. J. and Schnute, J. T.: Statistical models for estimating CPUE from catch and effort data, Can. J. Fish. Aquat. Sci., 49, 1315-1327, 1992.

Rothschild, B. J.: Fishing effort., in: Fish Population Dynamics, edited by: Gulland, J. A., John Wiley \& Sons, London, 1977.

Rubec, P. J., Jackson, A., Ashbaugh, C., and Versaggi, S: Development of an Electronic Logbook to Assess Shrimp-Trawl Catch, Effort, and Associated Environmental Data in Areas Fished off Florida and Texas, Am. Fish. Soc. Symp., 41, p. 320, 2005.

Santojanni, A., Arneri, E., Barry, C., Belardinelli, A., Cingolani, N., Giannetti, G., and Kirkwood, G.: Trends of anchovy (Engraulis encrasicolus,L.) biomass in the northern and central Adriatic, Sci. Mar., 67(3), 327-340, 2003.

Santojanni, A., Cingolani, N., Arneri, E., Kirkwood, G., Belardinelli, A., Giannetti, G., Colella, S., Donato, F., and Barry, C.: Stock assessment of sardine (Sardina pilchardus, Walb) in the Adriatic Sea, with estimate of discards, Sci. Mar., 69(4), 603617, 2005.

Santojanni, A., Arneri, E., Bernardini, V., Cingolani, N., Di Marco, M., and Russo, A.: Effects of environmental variables on recruitment of anchovy in the Adriatic Sea, Clim. Res., 31, 181-193, 2006.

Simpson, J. J.: Remote Sensing in fisheries: A tool better management in the utilization of a renewable resource, Can. J. Fish. Aquat. Sci., 51, 743-771, 1994.

Swartzman, G., Huang, G., and Kaluzny, S.: Spatial analysis of Bering Sea ground fish survey data using generalized additive models, Can. J. Fish. Aquat. Sci., 49, 1366-1378, 1992.

Venables, W. N. and Dichmont, C. M.: GLMs, GAM, and GLMMs: an overview of theory for applications in fisheries research., Fish. Res., 70, 319-337, 2004. 
Vichi, M., Zavatarelli, M., and Pinardi, N.: Seasonal modulation of microbially mediated carbon fluxes in the northern Adriatic Sea - a model study, Fish. Oceanogr., 7(3/4), 182-190, 1998.

Yáñez, E., Barbieri, M. A., Silva, C., Nieto, K., and Espiandola, F.: Climate variability and pelagic fisheries in northern Chile, Prog. Oceanogr., 49, 581-596, 2001.

Waluda, C. M., Rodhouse, P. G., Trathan, P. N., and Pierce, J.: Remotely sensed mesoscale oceanography and the distribution of Illex argentinus in the South Atlantic, Fish. Oceanogr., 10-2, 207-216, 2001.
Walsh, W. A. and Kleiber, P.: Generalized additive model and regression tree analyses of the blue shark (Prionace glauca) catch rates by the Hawaii-based commercial longline fishery, Fish. Res., 53, 115-131, 2001

Wessel, P. and Smith, W. H. F.: Free Software helps map and display data, EOS Trans AGU, 72, 441 and 445-446, 1991. 